\title{
The development of unfired earth bricks using seaweed biopolymers
}

\author{
C. Dove \\ University of Strathclyde, UK
}

\begin{abstract}
The construction industry has been at the forefront of scrutiny regarding the inefficient consumption of natural resources and energy intensive processes involved in the manufacture of materials. There is therefore a growing incentive to develop new building technologies which have a low environmental impact and can contribute positively to sustainable design strategies. The ambition of this research is to develop composite materials for building applications using biopolymers obtained from macro-algae. Macro-algae, or seaweed as it is more commonly known, is a renewable and abundant resource which contains various useful constituents which may be suitable for the development of new materials. This includes the biopolymer, alginate, which is the main structural polysaccharide of brown seaweeds. This study focusses specifically on the manufacture of unfired clay bricks which incorporate alginate as a binding agent in an effort to improve their strength. It is anticipated that these bricks could be utilised as an internal walling system, offering a low embodied energy alternative to other masonry systems such as fired brick and concrete. This study discusses the use of four different alginate products sourced from Scottish seaweeds which were used to produce small-scale unfired bricks. Properties such as the mechanical strength and shrinkage of the specimens have been investigated. Results have demonstrated that two of the alginate products improved both the compressive and flexural strength of the bricks but that the magnitude of the strength increase was dependent on the type of alginate used.

Keywords: biopolymer, biocomposite, alginate, CEB, adobe.
\end{abstract}




\section{Introduction}

\subsection{The use of natural materials in construction}

An increasing level of importance is being placed on the types of materials used in construction due to the energy consumption and greenhouse gas emissions associated with their production [1]. The use of natural materials as opposed to non-renewable and petroleum based products has been identified as a potential means for reducing the embodied energy and carbon footprint of buildings [2] as well as helping to create healthy and comfortable indoor environments. Whilst bio-based materials have a long history in construction technology, with more and more importance being placed on environmental assessments and life cycle analysis (LCA), the use of so called 'low impact' materials such as timber, strawbale, natural fibre insulations and earth-based materials are gaining popularity in the UK and this is now a growing area of research $[3,4]$.

\subsection{Unfired earth masonry}

As a readily available and abundant resource, raw earth has played a vital role in the development of mankind. It has been utilised as a building material for thousands of years, with examples of sun-dried or 'baked' bricks dating back to $7000 \mathrm{BC}$ having been discovered in Mesopotamia, Egypt and India [5]. In considering the global context, earth-based building techniques such as cob, adobe and rammed earth are of great significance, with an estimated one third of the worldwide population inhabiting buildings made from earth [6]. Whilst these various building methods have been used extensively in construction for centuries [7], in Western societies most of these materials have been replaced by contemporary forms of masonry such as fired bricks and concrete. In comparison to such materials, earth is considered to have a number of disadvantages such as relatively low mechanical strength and durability [8]. However raw earth still remains as a cheap, abundant and eco-friendly material and when detailed appropriately can be used to create beautiful and versatile architectural forms.

In the context of the UK, fired clay materials currently dominate the masonry market. Whilst earth based construction was commonplace in the UK and in Scotland until the $18^{\text {th }}$ century, this traditional building technique was considered to be labour intensive and experienced a decline as a result of the growing popularity of stone and timber [9]. Although the majority of earth based buildings in existence today are located in developing countries, a resurgence in more traditional earth building techniques has been witnessed in recent decades, particularly within Europe, the USA, Australia and New Zealand [10], and there have been an increasing number of studies looking into the potential of unfired earth as a contemporary building material. This is mainly a result of the growing recognition of earth's environmental credentials as well as its associated hygrothermal and acoustic benefits. It is estimated that there are currently around 500,000 earth buildings in existence in the UK [9] with modern methods of rammed earth construction and compressed earth blocks (CEB), a descendent of 
traditional adobe blocks, becoming particularly popular. The main barrier however, to the further development of this type of construction is the relatively low load bearing capacity of unfired earth which can limit its useful application. There is therefore a renewed incentive for developing strategies to improve the mechanical strength as well as the durability of earthen materials.

\subsubsection{Stabilisation techniques}

The principal method of improving the mechanical properties of raw earth is through stabilisation. For unfired bricks, which are the main focus of this study, the most common stabilisation method is through the use of additives like cement and lime and these are well documented in published literature. In the case of cement stabilisation, it is generally agreed that the inclusion of cement can lead to significant improvements in compressive strength and moisture resistance [1114]. However, as discussed by several authors, the use of cement generally comes at an environmental cost due to the energy-intensity and high $\mathrm{CO}_{2}$ burden associated with its manufacture $[10,15,16]$. Although lime has been recommended as a potential alternative to cement due to its perceived lower environmental impact, there is an on-going debate as to whether this is truly the case. For example, according to Hammond and Jones [17], the overall embodied energy of lime was actually shown to be greater than that of cement. In addition larger dosages of lime are required to achieve the same results seen with smaller quantities of cement and this further diminishes its ecological benefits. As a result, there are increasing efforts to find alternatives to cement and lime which offer more environmentally friendly solutions to improve the properties of unfired earth.

\subsubsection{Organic materials and biopolymers as stabilisers}

Various organic materials have been used historically in the production of earthen buildings with most techniques and dating back to the Roman era where the properties of a soil would be modified using locally available, natural products. These include plant based products such as vegetable oils [18, 19], various plant gums and resins [20] and molasses [21]. Animal products such as excrement, urine, blood, milk and animal glues have also been successfully used to enhance the properties of raw earth $[20,22,23]$. Although most of these traditional techniques are now rarely used owing to the development of new synthetic products, the principle behind the use of renewable bio-based additives has been receiving renewed attention in an effort to find alternatives to cement based systems. In particular, the use of biopolymers, sourced from renewable, non-food crops has been recognised as a potential constituent for construction materials. As discussed by Plank [24] and Vieira et al. [25], biopolymers like lignosulfonate, casein, derivatives of starch and cellulose and various water-soluble polysaccharides can be used as admixtures for masonry materials and used to modify the properties of products like concrete, cement and mortars. Eires et al. [22] also demonstrates that a wide range of biopolymers have been used specifically to modify the properties of clay-based materials, with examples ranging from linseed oil to cow dung. Therefore whilst there is clearly potential for natural biopolymers to be used as alternative stabilisers for earthen materials, 
further research into the appropriate types and the nature of the clay/biopolymer interaction is required.

\subsection{Alginate}

Alginate is an algal polysaccharide which is found in the cell walls of brown seaweeds, forming between $20-60 \%$ of the dry matter [26]. In terms of its chemical composition, alginate is a block co-polymer of (1-4)-linked $\beta$-D-mannuronic acid and $\alpha$-L-guluronic acid residues, commonly referred to as $\mathrm{M}$ and $\mathrm{G}$ blocks respectively. The ratio of these components and their sequence within the polymer chain depends on the seaweed source. Furthermore, different parts of the same algae have been found to offer varying alginate compositions depending on the role of the particular tissue within the organism. As such, the properties offered by alginates vary widely and can be easily tailored to suit the desired application. Alginate is a particularly useful form of hydrocolloid due to its unique and versatile gelling properties which makes it an ideal candidate in a wide range of stabilising and gel-forming applications. It is therefore commonly found in numerous commercial products ranging from processed foods and textile dyes to dental impression materials and drug delivery systems [27].

\subsubsection{Alginate as an additive for unfired masonry}

The use of alginate as a stabilising additive for soils has been documented in a few studies, mainly relating to ground-works and agricultural applications where the alginate is used to increase the stability of soil crumbs or used to aid plant growth $[28,29]$. However, in referring specifically to the use of either seaweed or alginate within building products, research has been limited only to a few studies. Minke [30], for example, refers to the use of seaweed as a density reducing additive for loam mixtures and Han et al. [31] also refer to the use of 'seaweed fibre' in a biocomposite building product. Achenza and Fenu [32] describe the use of a similar fibrous material obtained from seaweed in unfired adobe blocks. Lee et al. [33] have also invesigated the use of an agar based 'seaweed glue' solution in clay based composites for use in building applications. Agar is a similar material to alginate, obtained from red forms of seaweed (Rhodophyta) as opposed to brown seaweeds (Phaeophyceae) from which alginates are sourced. Within all of these studies there are limited details regarding the seaweed products used and this therefore raises questions regarding their source, chemical composition and their exact function within the described composites.

Regarding the specific use of alginate, the most detailed study conducted to date is that by Galán-Marín et al. [34] and Rivera-Gómez et al. [35]. This involved the development of a composite clay brick product which incorporates an alginate polymer and natural fibres as reinforcing elements. The stabilising effect achieved in this experiment is attributed to the ionic bridging which takes place between the alginate polymer and divalent calcium cations contained within soil. The results showed that the compressive strength was increased upon the addition of the two additives however this study focused primarily on the fibre content of the brick with less consideration being given to the role of the alginate. The authors also use a liquid based 'seaweed extract' with a dosage of $20 \%$ or a dental impression 
powder material with a dosage rate of $\sim 1 \%$. The 'seaweed extract' product has only a small percentage of dry matter (i.e. $<2 \%$ ) which is mixture of sodium alginate, sodium carbonate and inorganic salts. Similarly, with the dental impression powder, this type of material will contain a sodium alginate content of only $\sim 15 \%$ with the remainder being composed of diatomaceous earth fillers, calcium salts, setting aids, $\mathrm{pH}$ modifiers and flavourings [36]. Variations in dosage rates, increased alginate concentrations and different alginate sources have yet to be fully studied and to date no research group appears to have investigated the use of a pure sodium alginate product.

\section{Methodology}

\subsection{Materials}

\subsubsection{Soil}

The soil used to produce the specimens in this study was supplied by Ibstock Ltd, a local brick manufacturer. The soil properties are summarised in Table 1.

Table 1: $\quad$ Soil classification.

\begin{tabular}{|c|c|c|c|c|}
\hline \multirow{2}{*}{\multicolumn{2}{|c|}{$\begin{array}{l}\text { pH }(\mathrm{CaCl}) \\
\text { Loss on drying at } 105^{\circ} \mathrm{C} \\
(\%)\end{array}$}} & 7.3 & \multicolumn{2}{|l|}{ Compaction behaviour } \\
\hline & & $2.5 \%$ & $\begin{array}{l}\text { Maximum dry density } \\
\left(\mathrm{g} / \mathrm{cm}^{3}\right)\end{array}$ & 1.89 \\
\hline \multicolumn{2}{|c|}{$\begin{array}{l}\text { Loss on ignition at } 550^{\circ} \mathrm{C} \\
(\%)\end{array}$} & $6.1 \%$ & $\begin{array}{l}\text { Optimum moisture } \\
\text { content }(\%)\end{array}$ & $15 \%$ \\
\hline \multicolumn{3}{|c|}{ Particle size distribution } & \multicolumn{2}{|l|}{ Atterberg limits } \\
\hline $\begin{array}{l}\text { Sand and } \\
\text { gravel }\end{array}$ & $0.06 \mathrm{~mm}>$ & $12 \%$ & Plastic limit (\%) & $15.7 \%$ \\
\hline Silt & $0.002-0.06 \mathrm{~mm}$ & $68 \%$ & Liquid limit (\%) & $27.2 \%$ \\
\hline Clay & $<0.002 \mathrm{~mm}$ & $20 \%$ & Plasticity index (\%) & $11.5 \%$ \\
\hline \multicolumn{2}{|c|}{ Soil classification } & $\begin{array}{l}\text { Silt } \\
\text { Loam }\end{array}$ & $\begin{array}{l}\text { Clay mineralogy } \\
\text { (XRD) }\end{array}$ & $\begin{array}{l}\text { Main components: } \\
\text { Quartz, Kaolinite and } \\
\text { Muscovite }\end{array}$ \\
\hline
\end{tabular}

\subsubsection{Alginate types: LH stem and LH frond}

All of the alginate products used in this study were produced by Marine Biopolymers Ltd and were manufactured using Scottish seaweeds. In Scotland, brown macro-algae can be found in most coastal environments however the most abundant supplies are concentrated around the Outer Hebrides. The two most commonly found species in Scotland include Ascophyllum nodosum and Laminaria of which there are various common types including Laminaria hyperborea, Laminaria saccharina, and Laminaria digitata [37]. For the purposes of this study a total of four different products were studied (see Table 2) including two dried sodium alginate products, sourced from different parts of the Laminaria Hyperborea seaweed. As a comparison two 'residue' products, produced as byproducts to the main alginate extraction process, were also tested. These 'residue' 
products were in the form of a sludge-like material containing residual amounts of alginate which had not been fully removed during the main alginate separation process.

Table 2: Alginate source and properties.

\begin{tabular}{|l|l|c|c|c|}
\hline Specimen & Source & M/G ratio & $\begin{array}{c}\text { Moisture } \\
\text { content (\%) }\end{array}$ & $\begin{array}{c}\text { Alginate } \\
\text { content (\%) }\end{array}$ \\
\hline LHS - R & $\begin{array}{l}\text { Laminaria hyperborea } \\
\text { (stem*) - residue }\end{array}$ & High G & $91.0 \%$ & $\begin{array}{c}<10 \% \text { of dry } \\
\text { weight }\end{array}$ \\
\hline LHF - R & $\begin{array}{l}\text { Laminaria hyperborea } \\
\text { (frond**) - residue }\end{array}$ & Medium G & $89.5 \%$ & $\begin{array}{c}<10 \% \text { of dry } \\
\text { weight }\end{array}$ \\
\hline LHS & $\begin{array}{l}\text { Laminaria hyperborea } \\
\text { (stem) - dried alginate }\end{array}$ & High G & $11.1 \%$ & $\begin{array}{c}100 \% \text { of dry } \\
\text { weight }\end{array}$ \\
\hline LHF & $\begin{array}{l}\text { Laminaria hyperborea } \\
\text { (frond) - dried alginate }\end{array}$ & Medium G & $6.9 \%$ & $\begin{array}{c}100 \% \text { of dry } \\
\text { weight }\end{array}$ \\
\hline
\end{tabular}

*Stem $=$ stalk-like component which forms structural backbone

**Frond = leaf-like components which are attached to stem

\subsection{Specimen preparation}

The experimental methodology is based on the work of Galán-Marín [34] and relevant British Standards such BS EN 1015:1999 [42]. This involved preparing different mixes of soil, distilled water and the specified alginate product with three specimens being prepared for each batch. Mix proportions were adapted for each product to ensure that each batch contained a sodium alginate content of $\sim 0.1 \%$ (wt) and an overall water content $\sim 15 \%$ (wt) as shown in Table 3 .

Table 3: $\quad$ Mix compositions (per 1 brick specimen).

\begin{tabular}{|l|c|c|c|c|c|}
\hline Specimen & Soil (g) & $\begin{array}{c}\text { Alginate / } \\
\text { residue (g) }\end{array}$ & $\begin{array}{c}\text { Additional water } \\
\text { (ml) }\end{array}$ & $\begin{array}{c}\text { Approx. } \\
\text { alginate } \\
\text { content (\%) }\end{array}$ & $\begin{array}{c}\text { Overall } \\
\text { water } \\
\text { content (\%) }\end{array}$ \\
\hline Control & $425 \mathrm{~g}$ & - & $75 \mathrm{ml}$ & - & $15 \%$ \\
\hline Residues & $420 \mathrm{~g}$ & $70-80 \mathrm{~g}$ & $\begin{array}{c}\text { Adjusted } \\
\text { depending on } \\
\text { residue type }\end{array}$ & $0.1 \%$ & $15 \%$ \\
\hline $\begin{array}{l}\text { Dried } \\
\text { alginate }\end{array}$ & $425 \mathrm{~g}$ & $0.5 \mathrm{~g}$ & $75 \mathrm{ml}$ & $0.1 \%$ & $15 \%$ \\
\hline
\end{tabular}

The materials were then homogenised in a mortar mixer for no more than 3 minutes and then hand-compacted into steel moulds $(40 \times 40 \times 160 \mathrm{~mm})$ using a tamper. The filled moulds were then oven dried at $60^{\circ} \mathrm{C}$ for 24 hours and then removed from the moulds. After oven-drying, all samples were then stored at ambient temperature and humidity for a minimum of 14 days before testing. 


\subsection{Testing}

\subsubsection{Visual observations}

Initial observations were made regarding workability of the mixture and homogeneity of the prepared specimens with samples being labelled and photographed. Workability was labelled as 'good',' moderate' or 'poor' and homogeneity was categorised as 'minimal', 'moderate' or 'severe' based on visible surface cracking/defects.

\subsubsection{Mass, density and shrinkage}

The bulk density $(\rho)$ of the specimens was given as the ratio of the unit mass $(\mathrm{g})$ in grams to the unit volume $\left(\mathrm{cm}^{3}\right)$ as calculated from the specimen dimensions. Digital callipers were used to make all measurements. Linear drying shrinkage was calculated as the percentage decrease in length between the $160 \mathrm{~mm}$ length of the mould and the length of the dry specimen.

\subsubsection{Flexural strength (based on BS EN 1015-11:1999)}

This testing procedure, commonly known as a three point bending test, is used to determine a value for the flexural modulus of rupture. The bending test equipment consisted of two rollers on which the specimen rests. The distance between the two support rollers should be a $100 \mathrm{~mm} \pm 5 \mathrm{~mm}$. A third roller sits on top of the specimen at the midpoint. A load was then applied gradually to the upper roller using a Universal Testing Machine, ensuring that failure occurred between 30-90 $\mathrm{s}$ after the load was applied. The maximum load $(F)$ as well as the width $(b)$, depth $(d)$ and gauge length (l) were recorded for each specimen and used to obtain the flexural strength. Results were calculated to the nearest $0.01 \mathrm{~N} / \mathrm{mm}^{2}$ as an average of three specimens.

\subsubsection{Compressive strength (based on BS EN 1015-11:1999)}

The principle of this test is that half-brick specimens (Fig 1), generated from the flexural test, are loaded uniformly in compression in a direction perpendicular to the bed joints until failure occurs (Fig 2). The compressive strength value for the specimens was then derived from the maximum load $\left(F_{\max }\right)$ and the cross sectional

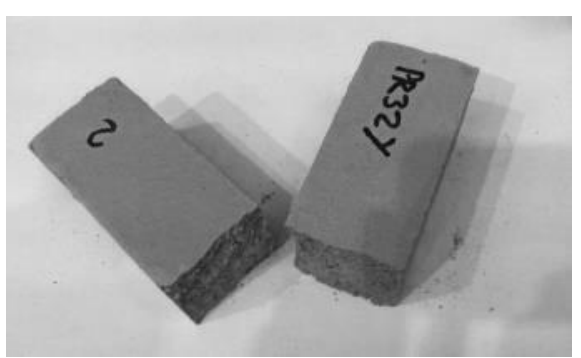

Figure 1: Brick specimen after flexural test.

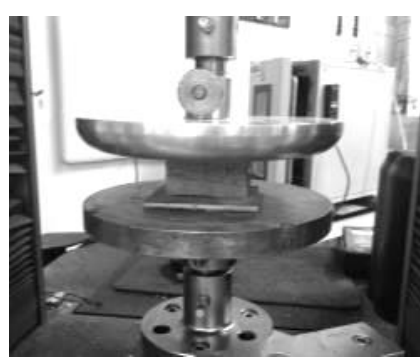

Figure 2: Compression testing. 
area of the specimen. The specimens were also sandwiched between two pieces of $3 \mathrm{~mm}$ plywood as recommended by Walker [38]. Platen restraint effects were also taken into account by using a correction factor which accounts for variations in specimen geometries, allowing values to be converted to unconfined compression strengths values [38].

\section{Results}

The results are shown in Table 4 and Figure 3.

Table 4: Summary of results for brick specimens.

\begin{tabular}{|c|c|c|c|c|c|c|c|}
\hline 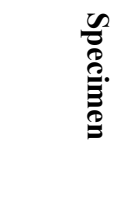 & 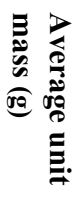 & 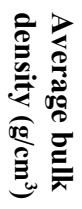 & 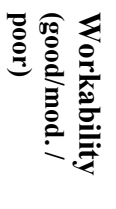 & 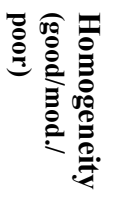 & 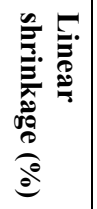 & 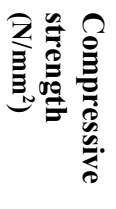 & 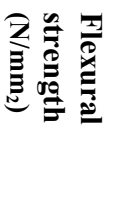 \\
\hline Control & 392 & 1.98 & Mod. & Mod. & $9 \%$ & 0.85 & 0.32 \\
\hline LHS-R & 390 & 1.69 & Good & Mod. & $4 \%$ & 0.58 & 0.44 \\
\hline LHF-R & 372 & 2.25 & Good & Mod. & $5 \%$ & 0.41 & 0.34 \\
\hline LHS & 416 & 1.90 & Good & Good & $5 \%$ & 1.64 & 0.95 \\
\hline LHF & 379 & 1.83 & Good & Good & $7 \%$ & 1.25 & 0.82 \\
\hline
\end{tabular}

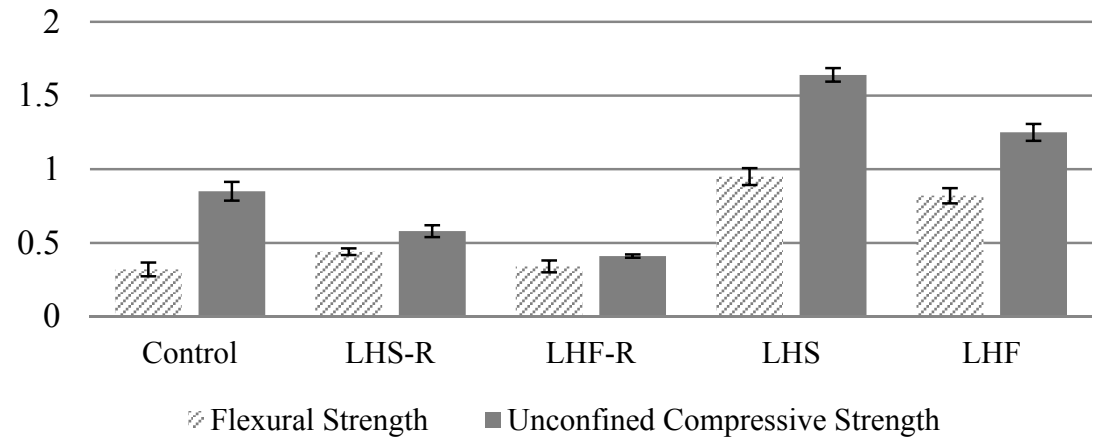

Figure 3: Flexural and compressive strength results $\left(\mathrm{N} / \mathrm{mm}^{2}\right)$.

\section{Discussion}

The visual observations revealed that in terms of workability, there was increased cohesiveness and plasticity during mixing due to gel-like nature of the alginate compared to using water alone. The homogeneity of the specimens was found to 
vary even between specimens of the same batch and it is therefore likely that the defects which occurred were largely due to variations in the manufacturing procedure. However generally, the LHS and LHF mixes had less defects and surface cracking compared to the other three batches.

The bulk densities of the specimens were found to be within the expected range for compressed earth blocks of 1.5 to $2 \mathrm{~g} / \mathrm{cm}^{3}$ [39] and close to the maximum dry density values for the given soil type $\left(1.89 \mathrm{~g} / \mathrm{cm}^{3}\right)$. Variations were likely due to experimental discrepancies in the level of compaction and the amount of material lost upon removal from the mould. In terms of the shrinkage values achieved, both the LHF and control specimens fell slightly outside the 3-6\% typical range suggested by Morton [40]. Fibrous materials such as straw are typically used to reduce drying shrinkage in earth materials and so the reductions witnessed due to the addition of both the residue products may be due to the fibrous cellulose components contained within this material.

The resulting values for flexural strength were broadly similar for the control and the two residue products however both of the alginate products showed increased values, with the LHS product in particular providing a flexural strength of $0.95 \mathrm{~N} / \mathrm{mm}^{2}$ which was almost three times the value of the control specimen. All of the products helped to increase the control mix beyond the $0.34 \mathrm{~N} / \mathrm{mm}^{2}$ criterion required by existing standards [41]. A similar pattern of results was observed with the compressive strength values with the LHS product again leading to the greatest increase and achieving a maximum compressive strength of $1.64 \mathrm{~N} / \mathrm{mm}^{2}$. However, none of the samples tested passed the minimum compressive strength of $2 \mathrm{~N} / \mathrm{mm}^{2}$ recommended by existing international standards for unfired earth blocks [41]. Although there may be some variation due to the hand-made nature of the bricks and the difficulty of controlling the degree of compaction, other factors such as the soil type and the alginate types used are likely to have contributed to the results. It is interesting to note that there was an observed difference between the stem and frond products with the stem-sourced products demonstrating a slight improvement for both the alginate and the residue. This is likely to have been caused by the different composition of the alginate polymer. The stem product will have a higher guluronic acid content and will consequently produce a stronger and more rigid gel network compared to the frond-derived products. It therefore seems logical that the LHS-R and LHS mixes have demonstrated higher compressive strength values than the equivalent frond products mixes.

\section{Conclusions}

When combined with other sustainable design strategies, the use of renewable materials can help to improve the whole life cycle impact of buildings. In the case of unfired earth, organic materials such as biopolymers can be used as low cost and environmentally friendly additives which modify important properties like mechanical strength. Alginate, and alginate by-products, are renewable and sustainably sourced materials which have the potential to be used as a locally sourced, bio-based admixture for earthen materials. 
This study has demonstrated that two of the alginate products (LHS and LHF) can be used to enhance the mechanical properties of unfired bricks, with the Laminaria hyperborea stem product providing the greatest increase in both flexural and compressive strength. However the compressive strength values achieved are still below the target value of $2 \mathrm{~N} / \mathrm{mm}^{2}$ and hence further research is required before these types of bricks could be used in practice. Whilst the two residue products studied improved workability, reduced shrinkage and marginally improved flexural strength, they also decreased the brick's compressive strength and are therefore considered unsuitable.

Recommendations for future studies include a comparison with different soil types, an investigation using increased alginate dosage rates and the use of alginates produced from different seaweed types. Furthermore, the brick prototypes produced in this study have been tested only in relation to structural performance and investigations into other properties of the product such as thermal performance, moisture absorption and long term durability still need to be conducted in order to evaluate the potential for commercial use.

\section{Acknowledgements}

The author wishes to thank Ibstock and MBL for supplying the materials and the Advanced Materials Research Laboratory and Chemical Processing and Engineering Department at the University of Strathclyde where the experimental work was conducted.

\section{References}

[1] B. Venkatarama Reddy and K. Jagadish, "Embodied energy of common and alternative building materials and technologies," Energy Build., vol. 35, no. 2, pp. 129-137, 2003.

[2] D. Felton, R. Fuller, and R. H. Crawford, "The potential for renewable materials to reduce the embodied energy and associated greenhouse gas emissions of medium-rise buildings," Archit. Sci. Rev., pp. 1-8, Sep. 2013.

[3] T. Woolley and N. Caleyron, "Overcoming the barriers to the greater development and use of environmentally friendly construction materials," presented at the Sustainable Building International Conference Proceedings, 2002.

[4] C. MacDougall, "Natural building materials in mainstream construction: lessons from the UK," J. Green Build., vol. 3, no. 3, pp. 1-14, 2008.

[5] E. W. Smith and G. S. Austin, Adobe, pressed-earth, and rammed-earth industries in New Mexico. New Mexico Bureau of Mines \& Mineral Resources, 1989.

[6] H. Houben and H. Guillaud, Earth construction: a comprehensive guide. Intermediate Technology Publications, 1994.

[7] C. Williams, S. Goodhew, R. Griffiths, and L. Watson, "The feasibility of earth block masonry for building sustainable walling in the United Kingdom,” J. Build. Apprais., vol. 6, no. 2, pp. 99-108, 2010. 
[8] O. Ruskulis, "Additives to Clay: Mineral and Synthetic Additives," Practical Action, Technical Brief, 2002.

[9] B. Little and M. Morton, "Building with Earth in Scotland," 2001.

[10] F. Pacheco-Torgal and S. Jalali, "Earth construction: Lessons from the past for future eco-efficient construction," Constr. Build. Mater., vol. 29, pp. 512-519, Apr. 2012.

[11] P. J. Walker, "Strength, durability and shrinkage characteristics of cement stabilised soil blocks," Cem. Concr. Compos., vol. 17, no. 4, pp. 301-310, 1995.

[12] P. Walker and T. Stace, "Properties of some cement stabilised compressed earth blocks and mortars," Mater. Struct., vol. 30, no. 9, pp. 545-551, 1997.

[13] A. Guettala, A. Abibsi, and H. Houari, "Durability study of stabilized earth concrete under both laboratory and climatic conditions exposure," Constr. Build. Mater., vol. 20, no. 3, pp. 119-127, Apr. 2006.

[14] J.-C. Morel, A. Pkla, and P. Walker, "Compressive strength testing of compressed earth blocks," Constr. Build. Mater., vol. 21, no. 2, pp. 303309, 2007.

[15] E. Worrell, L. Price, N. Martin, C. Hendriks, and L. O. Meida, "Carbon Dioxide Emissions from the Global Cement Industry," Annu. Rev. Energy Environ., vol. 26, no. 1, pp. 303-329, Nov. 2001.

[16] A. Hasanbeigi, L. Price, and E. Lin, "Emerging energy-efficiency and $\mathrm{CO}_{2}$ emission-reduction technologies for cement and concrete production: A technical review," Renew. Sustain. Energy Rev., vol. 16, no. 8, pp. 62206238, 2012.

[17] G. Hammond and C. Jones, Inventory of Carbon \& Energy: ICE. Sustainable Energy Research Team, Department of Mechanical Engineering, University of Bath, 2008.

[18] A. Ogacho, B. Aduda, and F. Nyongesa, "Thermal conductivity of a kaolinite refractory: effect of a plant-derived organic binder," J. Mater. Sci., vol. 38, no. 11, pp. 2293-2297, 2003.

[19] F. Balo and H. L. Yucel, "Assessment of Thermal Performance of Green Building Materials Produced with Plant Oils," Int. J. Mater. Sci., vol. 3, no. 3, 2013.

[20] O. Ruskulis, "Additives to Clay: Organic Additives," Practical Action, Technical Brief, 2002.

[21] B. Vilane, "Assessment of stabilisation of adobes by confined compression tests," Biosyst. Eng., vol. 106, no. 4, pp. 551-558, 2010.

[22] R. Eires, A. Camões, and S. Jalali, "Earth architecture: ancient and new methods for durability improvement," in Structures and Architecture: Concepts, Applications and Challenges, P. J. S. Cruz, Ed. London: Taylor and Francis Group, 2013.

[23] M. I. G. Beas, "Traditional architectural renders on earthen surfaces," MSc Thesis, University of Pennsylvania, 1991.

[24] J. Plank, "Applications of biopolymers and other biotechnological products in building materials," Appl. Microbiol. Biotechnol., vol. 66, no. 1, pp. 1-9, Nov. 2004. 
[25] M. Vieira, D. Klemm, L. Einfeldt, and G. Albrecht, "Dispersing agents for cement based on modified polysaccharides," Cem. Concr. Res., vol. 35, no. 5, pp. 883-890, 2005.

[26] B. Rehm, Alginates: Biology and applications, vol. 13. Springer, 2009.

[27] K. I. Draget, O. Smidsrød, and G. Skjåk-Bræk, "Alginates from algae," Biopolym. Online, 2005.

[28] J. Quastel and D. Webley, "The effects of the addition to soil of alginic acid and other forms of organic matter on soil aeration," J Agric Sci, vol. 37, pp. 257-266, 1947.

[29] W. Emerson, "Synthetic soil conditioners," J Agric Sci, vol. 47, no. 11, pp. 7-121, 1956.

[30] G. Minke, Building with earth. Birkhäuser, 2006.

[31] S.-O. Han, H.-S. Kim, Y.-J. Yoo, Y.-B. Seo, and M.-W. Lee, "Seaweed Fibre-Reinforced Biocomposite and Method for Producing the Same Using High-temperature Grinding," 03-May-2008.

[32] M. Achenza and L. Fenu, "On Earth Stabilization with Natural Polymers for Earth Masonry Construction," Mater. Struct., vol. 39, no. 1, pp. 21-27, Jan. 2006.

[33] K.-C. Lee, J.-H. Her, and S.-K. Kwon, "Red clay composites reinforced with polymeric binders," Constr. Build. Mater., vol. 22, no. 12, pp. 22922298, 2008.

[34] C. Galán-Marín, C. Rivera-Gómez, and J. Petric, “Clay-based composite stabilized with natural polymer and fibre," Constr. Build. Mater., vol. 24, no. 8, pp. 1462-1468, 2010.

[35] C. Rivera-Gómez, C. Galán-Marín, and F. Bradley, "Analysis of the Influence of the Fiber Type in Polymer Matrix/Fiber Bond Using Natural Organic Polymer Stabilizer,” Polymers, vol. 6, no. 4, pp. 977-994, 2014.

[36] W. Cook, "Alginate dental impression materials: Chemistry, structure, and properties," J. Biomed. Mater. Res., vol. 20, no. 1, pp. 1-24, Jan. 1986.

[37] M. T. Burrows, M. Macleod, and K. Orr, "Mapping the intertidal seaweed resources of the Outer Hebrides," S.A.M.S \& Hebridean Seaweed Company, Scottish Association for Marine Science Internal Report No. 269, 2010.

[38] P. J. Walker, "Strength and erosion characteristics of earth blocks and earth block masonry," J. Mater. Civ. Eng., vol. 16, no. 5, pp. 497-506, 2004.

[39] F. V. Riza, I. A. Rahman, and A. M. A. Zaidi, "A Brief Review of Compressed Stabilized Earth Brick (CSEB)," presented at the Science and Social Research (CSSR), 2010 International Conference on, 2010, pp. 9991004.

[40] T. Morton, Earth masonry: Design and construction guidelines. IHS BRE Press, 2008.

[41] Government of New Mexico, "2009 New Mexico Earthen Building Materials Code," NMAC 14.7.4, 2009.

[42] BS EN 1015-11:1999 British Standard Institute, "Methods of test for mortar for masonry: Part 11", 1999. 